\title{
Does Technology Innovation Reduce Haze Pollution? An Empirical Study Based on Urban Innovation Index in China
}

\section{Lingyun $\mathrm{He}$}

Zhongnan University of Economics and Law

\section{Enyu Yuan}

Zhongnan University of Economics and Law

\section{Kexin Yang}

Wuhan University

Dongjie Tao ( $\nabla$ taodongjie@hbue.edu.cn )

Hubei University of Economics https://orcid.org/0000-0002-4016-294X

\section{Research Article}

Keywords: urban innovation, haze pollution, technological progress, PM2.5 concentration

Posted Date: July 8th, 2021

DOI: https://doi.org/10.21203/rs.3.rs-586766/v1

License: (9) This work is licensed under a Creative Commons Attribution 4.0 International License. Read Full License

Version of Record: A version of this preprint was published at Environmental Science and Pollution Research on November 25th, 2021. See the published version at https://doi.org/10.1007/s11356-02117448-9. 


\title{
Does technology innovation reduce haze pollution? An empirical
}

$$
\text { study based on urban innovation index in China }
$$

\author{
Lingyun He, Enyu Yuan, Kexin Yang and Dongjie Tao*
}

\begin{abstract}
Haze pollution is one of the most concerned environmental issue, it is of great significance to control haze pollution without affecting economic development. Using the panel data composed of PM2.5 concentration and other data from 278 cities in China between 2003 to 2016, this paper empirically investigates the impact of urban innovation on haze pollution and its transmission mechanism. Based on the fixed effect model, the research finds that the increase of urban innovation significantly reduced haze pollution. The result still holds after dealing with possible endogenous problems. Energy consumption and industrial agglomeration are two important transmission channels through which urban innovation affects haze pollution. Furthermore, time heterogeneity analysis shows that the negative effect of urban innovation on haze pollution increases with time. Spatial heterogeneity analysis shows that urban innovation has a greater mitigation effect on haze pollution in eastern cities than in central and western cities in China. This paper indicates that technological innovation as the main driving force for development, can provide strong support for China to achieve the aims of improving the ecological environment.
\end{abstract}

Keywords: urban innovation; haze pollution; technological progress; PM2.5 concentration

\section{Introduction}

Haze pollution is a kind of air pollution phenomenon that has occurred all over the world. As a common "urban disease", "haze" not only affects economic growth, but also endangers the health of residents. In recent years, large-scale fog and haze weather appeared frequently in Chinese cities. Although China has experienced the miracle of rapid economic growth for decades, along with this process, the factories emit large amount of pollutants and construction sites generated a lot of dust. According to most recent statistics from ministry of ecology and environment of China, 239 prefecture-level cities have a problem with excess air pollutants. China is committing to transform the

${ }^{*}$ Corresponding author: Dongjie Tao

Postal address: School of Public Finance and Administration, Hubei University of Economics, No.8, yangqiaohu Avenue, Canglong Island Development Zone, Jiangxia District, Wuhan, Hubei Province, China

E-mail: taodongjie@hbue.edu.cn TEL:+8613296509070

Lingyun He

Economics School, Zhongnan University of Economics and Law, No.182 Nanhu Avenue, Donghu High-tech Zone, Wuhan, Hubei, China

Enyu Yuan

Economics School, Zhongnan University of Economics and Law, No.182 Nanhu Avenue, Donghu High-tech Zone, Wuhan, Hubei, China

Kexin Yang

Economics School, Wuhan University, No.299, Bayi Road, Wuchang District, Wuhan City, Hubei Province, China 
economic development pattern to environment-friendly development; both the government and the society attach great importance to air pollution and other environmental problems.

The fundamental requirements for improving air quality are not only to reduce the frequency of haze problems by setting pollutants discharge or emission standards and enhancing environmental regulations, but also, more importantly to address the root causes of air pollution. The fundamental path to improve air quality is to improve energy and resource efficiency through technological innovation to reduce pollutant emissions. Actually, innovation is now a city-based phenomenon (2thinknow, 2006) ${ }^{1}$, cities can gather research and development $(R \& D)$ resources, and form scale effects. Everywhere in the Western world we can see the rise of cities calling themselves "innovative cities" (Hospers, 2008). Since 2008, China has gradually promoted the construction of "innovative cities" and proposed to improve the urban innovation level. It is of great significance to study does urban agglomeration of innovation activities affect haze pollution.

In the context of balancing environmental pollution and economic growth, this paper applies the fix effect model to test the effect of urban innovation on PM2.5 concentration in China based on prefecture-level cities data. The regression results suggest that the urban innovation level increased by $1 \%$, the PM2.5 concentration would be decreased by 1.030 . It then attempts to address the transmission mechanisms of urban innovation on PM2.5 concentration, and the heterogeneity of the effect of different time periods and geographical regions. We conduct robustness through different models to check whether the effect is robust in China. Moreover, this study also tests effect of urban innovation on other components of haze.

This paper contributes to the literature in two aspects. Firstly, our article contributes to the stand of literature that connects innovation and environment. In view of the availability of data, most of the current studies used R\&D expenditure and the number of patent grants to measure the level of innovation and have looked mainly at the impact of technological progress within enterprises and provinces on pollution, this paper uses the urban innovation index that takes into account the market value of patents to measure the level of innovation and makes the first attempt to analyze the impact in the framework of city. Secondly, a grow body of papers study the role of technological innovation in energy consumption and carbon emissions. However, the effect of innovation on PM2.5 concentration and the heterogeneity of the effect of different time periods and geographical regions have not yet received sufficient attention. This paper extends this topic and sheds more light on the pollution reduction effects of innovation. Besides, this paper adds to the existing literature in performing a robust estimation check. We not only exploit the interactive fixed effect model to take the multidimensional time shock into account, but also use dynamic panel model to control the effect of previous period. Moreover, we rely on data covers a wide area of the city and has a long observation period in China: we exploit the nonpoint source data of PM2.5 concentration measured by satellite-observed from Columbia University's NASA Social Economic Data and Application Center, whereas other identification of related studies have been limited by the lack of long-term monitoring data in developing countries where PM2.5 concentration sites are sparse and have only been established in recent years in several cities. Our estimates of the effect are more accurate and contributing to current policy discussions on haze governance.

1 Source: https://www.innovation-cities.com/ 


\section{Literature review and hypothesis}

Scholars have long been concerned with the impact of technological innovation on environmental pollution. The IPAT model proposed by Ehrlich and Holdren (1971) suggested that technological advances can alleviate environmental pollution caused by population growth. Grossman and Krueger (1991) argued that economic growth means the continuous development of high technology, which is conducive to reducing environmental pollution. The methods and models provided by these two documents are still widely used today, and their research conclusions have been confirmed by many studies. Innovative capabilities have promoted the successful implementation of pollution prevention, pollution control and clean technology strategies (Prakash and Potoski, 2006; Bhupendra and Sangle, 2015). The advancement of environmentally sound technology in production is conductive to reducing the discharge of pollutants and improving the efficiency of pollution control, thereby helping to suppress environmental pollution (Johnstone et al. 2017; Ge, 2019; Valentin and Elena, 2020). Based on these theoretical analyses, a growing body of literature conducted empirical research on the impact of innovation and pollution.

Some empirical studies explore the relationship between innovation and pollution from the perspective of technological advancement and pollution emissions at the micro level. Levinson (2009) studied data from the US Environmental Protection Agency (EPA) to show that the overall pollution reduction of US manufacturing industry comes mainly from changes in technology. Baniak and Dubina (2012) believed that domestic independent technology innovation, foreign technology import and domestic technology transfer improved eco-efficiency of industrial enterprises. Wan et al. (2015) focused on the industrial enterprises of China, and also confirmed that the positive role of three modes of technological innovation in environment. Zhang et al. (2019) proposed an index system to calculate technological innovation efficiency and verified that technological innovation is conductive to improving the capacities of industrial enterprises to deal with local environmental pollutant emissions, thereby reducing environmental pollution. Ge (2019) also believed that enterprise technology innovation is conductive to reducing pollution emission, including waste water, waste gas, and solid waste. $\mathrm{Xu}$ et al. (2020) used the panel data of 28 sub-sectors of China's manufacturing industry from 2011 to 2017 and found that innovation capabilities have a positive effect on the suppression of environmental pollution.

Past research has also examined associations between innovation and pollution from macro-level, national technological advancement and pollution emissions. Dinda (2018) conducted research on United States' technological progress and believed that technological progress is the central force that causes $\mathrm{CO}_{2}$ emissions' reduction. Nyarko et al. (2018) found that technological advancement in OCED countries plays a key role towards mitigation of $\mathrm{CO}_{2}$ emissions. Ibrahiem (2020) and Nguyen et al. (2020) also reached similar conclusions in Egypt and 13 selected G-20 countries. In addition, scholars have also studied the relationship between innovation and environmental pollution at the provincial level. Wang and Xie (2014) used the total R\&D expenditure of large and medium-sized enterprises in China's province to measure the province's technological innovation level, and proved that technological innovation is beneficial to reducing $\mathrm{SO}_{2}$ emissions. Liu (2018) used a similar approach to measure the province's innovation level in China, and found that technological innovation can reduce annual average concentrations of PM10. Ma et al. (2020) used the number of patents granted to measure the province's innovation level, and discovered that, technological innovation can reduce 
pollution between $0.167 \%$ and $0.415 \%$ under different water pollution intensity. Wu (2020) used a similar method to measure the level of technological innovation in China's provinces and reached similar conclusions.

Although the above research generally believed that technological innovation is conducive to reducing pollution, a few studies hold different views. For example, Acemoglu et al. (2012) gave theoretical evidence of the existence of endogenous technological progress, and found that new technologies can be divided into clean and pollution-based categories. Therefore, the direction of technical change will significantly affect environmental pollution. Giuliani (2018) accounted that innovation-induced industrial activities have had important negative consequences for the environment. Demir et al. (2019) discovered that the relationship between $\mathrm{CO}_{2}$ emission level and number of domestic patents depicts an inverted U-shape curve for Turkey.

Research on innovation and environmental pollution has not yet reached a consistent conclusion, and little attention has been paid to haze pollution. In addition, there is no existing research on urban innovation level and environmental pollution. Moreover, the existing measurement of regional innovation level mainly uses methods such as the total $R \& D$ expenditure of enterprises in the region or the number of patent authorizations in the region (Wang and Xie, 2014; Liu, 2018; Ma, 2020; $\mathrm{Wu}, 2020)$. However, the former is difficult to avoid statistical errors, and the latter does not consider the market value of patents. Therefore, it cannot accurately represent the level of regional innovation. This paper will address the shortcomings of the previous studies in these aspects, and investigate the impact of urban innovation on haze pollution.

One of the mechanisms that influences urban innovation regarding haze pollution is energy consumption. On the one hand, an increase in energy efficiency and a reduction in energy consumption will lead directly to a reduction in pollutant emissions, thereby reducing haze pollution. Scholars have reached a consensus on the negative effects of energy consumption on environmental quality. In terms of energy consumption, Apergis and Payne (2014) used cross-continental data to undertake their research, finding a significant correlation between energy consumption and environmental quality. Hafeez et al. (2019) believed that energy consumption is one of the main determinants of environmental degradation. In terms of energy structure, Yang et al. (2018) considered that the improvement of energy structure has made a significant contribution to improving environmental quality. On the other hand, innovation is a key force in improving energy efficiency and reducing energy consumption. For instance, Fisher et al. (2006) argued that capital-saving technological innovation is the most critical factor in relation to improving energy efficiency in China. Cagno et al. (2015) research on Italian foundry companies and Subrahmanya and Kumar's (2011) research on small and medium-sized enterprises in the Indian machine tool industry both concluded that technological innovation activities have promoted the improvement in energy efficiency. Studies by Ramirez-Portilla et al. (2014), Herrerias et al. (2016) and Zeng and Li (2020) also confirmed the important role of innovation in improving energy efficiency and reducing energy consumption. Therefore, we expect that urban innovation reduces haze pollution by improving energy efficiency and reducing energy consumption.

Another important mechanism of urban innovation for haze pollution is industrial agglomeration. On one hand, there are economies of scale environmental pollutant emissions and treatment (Lu and Feng, 2014), and agglomeration of economic activities are found to have a reducing effect on environmental pollution. Daddi et al. (2017) thought that the improvement of environmental pollution 
reduction efficiency can be achieved through cooperation and infrastructure sharing between enterprises. Porter (1998), Chertow (2008), and Hosoe and Naito (2006) believed that the technology spillover effect of industrial agglomeration may promote the emergence and development of environmentally related industry clusters and positively affect the spread of clean technology. From the perspective of the positive externalities of industrial agglomeration, Copeland and Taylor (1994) also confirmed that the scale effect brought by industrial agglomeration can increase the scale of returns of pollution control technologies across the whole industry, thus improving the environment quality. On the other hand, innovation is conducive to the integration of factors and is an important force to promote industrial agglomeration. Marshall (1890) proposed that inter-firm technological spillovers can promote the spatial agglomeration of manufacturing production. In other studies, scholars have reached similar conclusions. For instance, Forman et al. (2016) found that technological innovation is important for inducing industrial space agglomeration. Sultan and Dijk (2017) believed that innovation was necessary to foster the development of industrial clusters. Chung and Alcácer (2002), Guastella and Van Oort (2015) and Goldman et al. (2016) argued that regional space agglomeration of innovation was an important source for industrial agglomeration. Based on the above analysis, we propose the following hypothesis that urban innovation is positively related to industrial agglomeration, which in turn negatively affect the haze pollution.

\section{Model and data}

\subsection{Model}

To investigate the impact of urban innovation on haze pollution, the basic econometric model can be specified as follows:

$$
P M 2.5_{i t}=\alpha_{0}+\alpha_{1} \ln \text { UrbanInno }_{i t}+\alpha_{j} X_{i t}+\mu_{i}+\varepsilon_{i t}
$$

In Equation (1), PM2.5 is the concentration of fine particles in the air, indicating the level of haze pollution. LnUrbanInno indicates the logarithmic urban innovation, and its coefficient $\alpha_{l}$ measures the impact of urban innovation on haze pollution, which is the core parameter we primarily focus on. $X$ represents the set of control variables, including economic development level, government technology investment, government environmental regulation, spatial structure, urban informatization level, human capital status, and the level of opening up. $\mu_{i}$ is the city fixed effect, and $\varepsilon_{i t}$ is random error term.

This article also employs a two-way fixed effect regression models to determine the effect of urban innovation on haze pollution, the model is proposed as below:

$$
P M 2.5_{i t}=\alpha_{0}+\alpha_{1} \ln \text { UrbanInno }_{i t}+\alpha_{j} X_{i t}+\mu_{i}+\eta_{t}+\varepsilon_{i t}
$$

Because the current haze pollution will not affect the historical level of urban innovation, we also use lags of explanatory variable in Equation (1) as explanatory variables and perform regression analysis to deal with possible reverse causality bias.

We also exploit the difference model which takes a time difference value for each variable in Equation (1) to form a new model for the robustness check. The difference model is set as Equation (3).

$$
\Delta P M 2.5_{i t}=\alpha_{0}+\alpha_{1} \Delta \ln \text { UrbanInno }_{i t}+\alpha_{j} \Delta X_{i t}+\Delta \mu_{i}+\varepsilon_{i t}
$$


As the PM2.5 in the last period may affect the current period, this paper also adds the lag term of PM2.5 on the right side of Equation (1) to construct a dynamic panel model for research. The dynamic panel model is set as Equation (4).

$$
P M 2.5_{i t}=\alpha_{0}+P M 2.5_{t-1}+\alpha_{1} \ln \text { UrbanInno }_{i t}+\alpha_{j} X_{i t}+\mu_{i}+\eta_{t}+\varepsilon_{i t}
$$

Referring to the mechanism analysis methods of scholars such as Chen and Chen (2018), this paper studies the transmission mechanism of urban innovation on haze pollution from energy consumption and industrial agglomeration channels. The specific empirical test steps are divided into two phases. The first phase verifies the effects of urban innovation on reducing energy consumption $(E n C s u)$ and promoting industrial agglomeration (lnduAgg). The second phase verifies the influence of two effects of urban innovation on haze pollution.

The first stage:

Examine the impacts of urban innovation on energy consumption and industrial agglomeration:

$$
\operatorname{InduAgg}(\operatorname{EnCsu})_{i t}=\beta_{0}+\beta_{1} \ln \operatorname{UrbanInno}_{i t}+\beta_{j} X_{i j t}+\mu_{i}+\eta_{t}+\varepsilon_{i t}
$$

The second stage:

Examine the impacts of energy consumption and industrial agglomeration on haze pollution:

$$
P M 2.5_{i t}=\gamma_{0}+\gamma_{1} \operatorname{InduAgg}(\operatorname{EnCsu})+\gamma_{j} X_{i t}+\mu_{i}+\eta_{t}+\varepsilon_{i t}
$$

\subsection{Data and variables}

\subsubsection{Independent variable}

The indicators of urban innovation are derived from the innovation index of 338 cities in 2003-2016 in the China Urban and Industrial Innovation Report 2017 (hereinafter referred to as "Report") of Fudan University Industrial Development Research Center. The Report uses the invention patents granted by China National Intellectual Property Administration. However, different from using the total number of patents to measure city's innovation level in the previous research, the calculation method of innovation index in the Report has been further optimized.

Firstly, the Report only use the number of invention patents that best represent innovation capabilities as a statistical basis. Other forms of patents only need to satisfy a certain degree of practicability and novelty, while invention patents need to satisfy the three characteristics of practicability, novelty and creativity, so they can best represent innovation capabilities.

Secondly, the value difference of patents is fully considered through the measurement method. Patent holders need to pay an annual fee to update the duration of the patent. Generally speaking, the older the patent's duration, the greater the private value. Therefore, existing studies that directly use the number of patents to measure innovation are not accurate and reasonable. The Report uses a patent update model to estimate the average value of patents of different ages. On this basis, the value of each patent is added to the city level to obtain the city innovation index.

\subsubsection{Dependent variable}

The dependent variable in this paper is the urban haze pollution, which is measured by the concentration of PM2.5 in the air. Haze pollution in China typically encompasses a large geographic area in these years, millions of people have suffered from haze weather. There is a haze extreme in January 2013, the hazardous dense haze covered more than 1 million $\mathrm{km}^{2}$ of China, the number of 
serious haze days in the central and eastern regions was generally more than 5 days, and parts of these area reached 10 to 20 days. In the face of severe air pollution, Chinese State Council issued the "Air Pollution Prevention Action Plan", and set a goal of reducing the concentration of PM2.5 in the air. Since then, the overall air quality has improved a little, but the occurrence of haze pollution is repetitive and difficult to control. Every autumn and winter season, many cities in some provinces such as Hebei, Shanxi, Shandong and Henan are covered by haze with long duration and heavy pollution. Inhalation of the pollutants by residents can irritate the respiratory system, induce and exacerbate related diseases. The low visibility weather also leads to high-speed road closures and flight delays. The factories have to cut production or stop production and cities will suffer huge economic losses. Based on the Chinese central and local Government Work Report and the key work plan of the Ministry of Environmental Protection in recent years, haze management is still one of the core contents of environmental protection.

PM2.5 concentration has been the primary haze pollutant and the PM2.5 data are obtained from the NASA Socioeconomic Data and Application Center of Columbia University. Multiple satellite-mounted devices measure the aerosol optical depth (AOD) of aerosol systems in the air, and geographically weighted regression (GWR) is combined with global ground measurements to estimate the annual mean PM2.5 concentration for various cities in the world from 1998 to 2016 (Van Donkelaar et al., 2018). It belongs to the nonpoint source data and has wider coverage than the ground point source monitoring data. Also it can more fully reflect the regional PM2.5 concentration and its variation characteristics, and the data has been widely used in various studies. In addition to PM2.5, sulfur dioxide and nitrogen oxides are also the important factors that constitute haze. Therefore, the concentration of $\mathrm{SO}_{2}$ and $\mathrm{NO}_{2}$ in air is also used as a dependent variable.

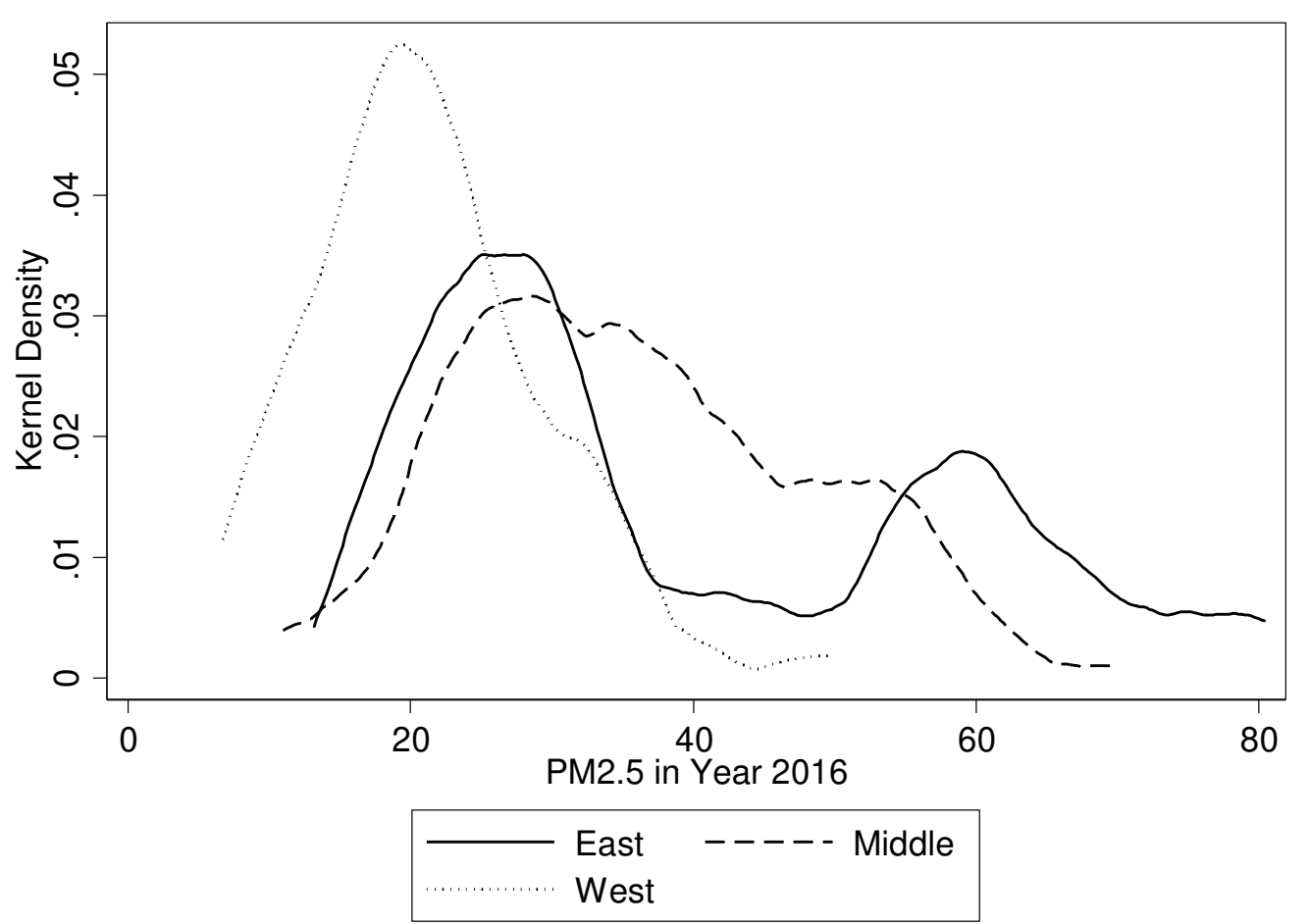


Figure 1 displays the kernel density estimation of PM2.5 for 2016 in the eastern, central and western regions of China. As can be seen, the level of haze pollution in the eastern coastal areas of China is lower than that in the central regions on the whole. This is closely related to the fact that the eastern part of China has always been at the forefront of opening-up, actively developing high-tech industries and optimizing the environment for innovation. Of course, a small number of cities in eastern China still have serious haze pollution due to the large size of the city and the high population density. China's western regions are relatively underdeveloped and less industrialized, so the overall level of haze pollution is low.

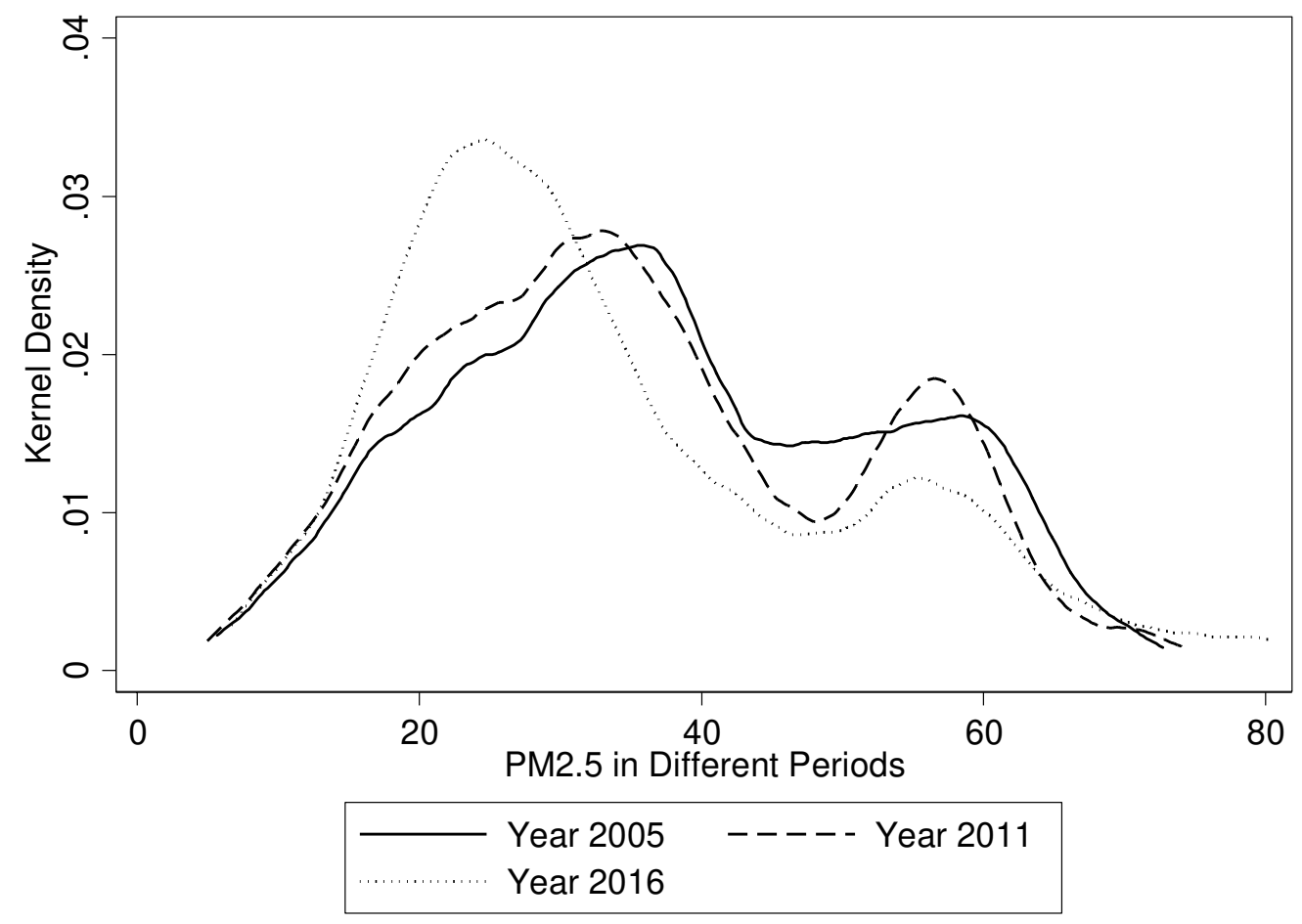

Figure 2 Kernel Density Estimation of PM2.5 Concentration in different periods

Figure 2 displays the kernel density estimation of PM2.5 concentration in different periods of China. The figure shows that from 2005 to 2011 and to 2016, the concentration of PM2.5 in the air has a decreasing trend, and the haze pollution is gradually alleviating. In the process of promoting economic growth, China has once sacrificed its environmental quality to some extent. However, in recent years, China has embarked on the path of green and sustainable development, and has tried to drive economic growth by optimizing resource allocation, promoting technological progress and enhancing the levels of urban innovation.

In order to deal with the omitted variable problem, some control variables are controlled in model (1). The names and construction methods of the variables are as follows. The level of economic development is measured by the per capita GDP and the data is deflated to exclude the price factor; Government science and technology investment is measured by the logarithm of per capita government science and technology expenditure; The degree of government environmental regulation is measured by the green coverage rate of the built-up area; The human capital is represented by the logarithm of the number of college students per 10,000; The level of informatization is measured by the logarithm of 
the number of Internet users in city; The FDI is measured by the proportion of foreign direct investment in GDP. In the Equation (2) and (3) which are used to study the transmission mechanism of urban innovation on haze pollution, energy consumption is measured by the logarithm of electricity consumption per capita; Industrial agglomeration is measured by the location quotient. The location quotient index can reflect the spatial distribution of geographical factors more realistically, and can also eliminate the regional scale difference factors (Li and Zhang, 2013; Yang, 2013). The data above are all from the China National Bureau of Statistics. Descriptive statistics of variables used in the study are shown in TABLE 1.

TABLE 1 Descriptive statistics of variables

\begin{tabular}{|c|c|c|c|c|}
\hline Variable & Definition/Unit & Sample & Mean & Std. Dev \\
\hline PM2.5 & $\mu \mathrm{g} / \mathrm{m}^{3}$ & 3892 & 37.104 & 16.24 \\
\hline LnUrbanInnov & $\begin{array}{l}\text { the logarithm of Urban } \\
\text { Innovation Index }\end{array}$ & 3886 & -0.273 & 1.893 \\
\hline InduAgg & Industrial agglomeration & 3892 & 2.133 & 0.683 \\
\hline Indusland & Industrial land occupancy & 3822 & 0.200 & 0.103 \\
\hline Gscitech & $\begin{array}{l}\text { Government scientific and } \\
\text { technological investment }\end{array}$ & 3889 & 3.142 & 1.757 \\
\hline Ecodev & $\begin{array}{c}\text { The level of economic } \\
\text { development }\end{array}$ & 3890 & 9.826 & 0.791 \\
\hline Enviregu & Environmental regulation & 3853 & 36.388 & 7.821 \\
\hline FDI & $\%$ & 3725 & 2.165 & 2.355 \\
\hline Humanc & Human capital & 3789 & 10.292 & 1.377 \\
\hline Informatization & The level of informatization & 3870 & 12.435 & 1.237 \\
\hline EnCsu & Energy consumption & 3805 & 8.166 & 0.881 \\
\hline $\mathrm{SO}_{2}$ & $\mu \mathrm{g} / \mathrm{m}^{3}$ & 695 & 39.146 & 22.066 \\
\hline $\mathrm{NO}_{2}$ & $\mu \mathrm{g} / \mathrm{m}^{3}$ & 695 & 39.913 & 12.234 \\
\hline
\end{tabular}

\section{Empirical results and analysis}

\subsection{Baseline Results}

PM2.5 is the main component of haze pollution. This section first explores the impact of urban innovation on PM2.5 concentration in the air. Column (1) of TABLE 2 reports the baseline regression results of the Equation (1). In controlling the urban characteristics such as the level of economic development, industrial land occupancy, the city government's scientific and technological expenditure and environmental regulation, and other factors that may lead to omitted variable bias, and considering city fixed effect at the same time, urban innovation are significantly negatively correlated with haze pollution. Due to the reverse impact of haze pollution on urban innovation, we also use lags of explanatory variable in Equation (1) as explanatory variables and perform regression analysis to deal 
with possible reverse causality bias. The regression results reported in column (5) of TABLE 2 suggest a negative association between urban innovation and haze pollution.

Moreover, this paper adds the time fixed effect and constructs a two-way fixed effect model for regression analysis, as shown in column (2) of TABLE 2. The logarithm of urban innovation index coefficient is 1.030 , which is a significant negative value, indicating a significant negative correlation in PM2.5 concentration. Assuming that the urban innovation level increased by $1 \%$, the PM2.5 concentration would be decreased by 1.030. Likewise, in order to deal with the reverse causal bias, we lag the explanatory variables in the two-way fixed effect model for one phase for regression analysis, and the regression coefficient of the lags of urban innovation has not changed fundamentally. We also add control variables the interaction term between city fixed effect and time trend to control the individual time trends in each city, the results in column (3) that urban innovation is significantly negatively correlated with haze pollution. The shocks over time may have different effects on different cities, and it may be multi-dimensional, thereby this paper also constructs an interactive fixed-effects model for regression analysis. The pollution reduction effect of urban innovation still exists, as shown in column (4).

The findings of our study imply that urban innovation matters for the reduction of haze emissions, which is in line with most of the previous research. Baniak and Dubina (2012), Zhang et al. (2019), Ge (2019) found that enterprise technological progress is conductive to reducing pollution; Liu (2018), Ma (2020), Wu (2020) proved that technological innovation at the provincial level in China is beneficial to reducing pollution. This paper makes the first attempt to analyze the impact of innovation on environmental pollution in the framework of city. In addition, our study concentrates on haze pollution, which has been less concerned by previous studies, and reaches a conclusion consistent with most of the previous research. Different from the existing research that used R\&D expenditure and the number of patent grants to measure the level of innovation of enterprises or regions, this paper uses the urban innovation index that takes into account the market value of patents to measure the level of urban innovation, which effectively reduce the estimation bias caused by the inaccurate measurement of the innovation level in the previous research. Moreover, this paper is the first to exploit the interactive fixed effect model to take the multidimensional time shock into account, which ensure the robustness of the finding that technological innovation matters for the reduction of environmental pollution.

TABLE 2 Impact of urban innovation on PM2.5 concentration: Baseline regression

\begin{tabular}{|c|c|c|c|c|c|c|c|}
\hline & (1) & (2) & (3) & (4) & & $(5)$ & (6) \\
\hline & PM2.5 & PM2.5 & PM2.5 & PM2.5 & & PM2.5 & PM2.5 \\
\hline LnUrbanInnov & $\begin{array}{c}-1.983 * * * \\
(0.193)\end{array}$ & $\begin{array}{c}-1.030 * * * \\
(0.239)\end{array}$ & $\begin{array}{c}-1.457 * * * \\
(0.408)\end{array}$ & $\begin{array}{c}-0.423 * * \\
(0.189)\end{array}$ & L. LnUrbanInnov & $\begin{array}{c}-1.607 * * * \\
(0.224)\end{array}$ & $\begin{array}{c}-1.251 * * * \\
(0.281)\end{array}$ \\
\hline Ecodev & $\begin{array}{c}6.139 * * * \\
(0.973)\end{array}$ & $\begin{array}{c}0.312 \\
(1.651)\end{array}$ & $\begin{array}{l}-3.437 \\
(3.549)\end{array}$ & $\begin{array}{c}1.326 \\
(1.484)\end{array}$ & L. Ecodev & $\begin{array}{c}8.438 * * * \\
(1.139)\end{array}$ & $\begin{array}{c}1.376 \\
(1.680)\end{array}$ \\
\hline Indusland & $\begin{array}{c}5.167 * * * \\
(1.390)\end{array}$ & $\begin{array}{c}3.566 * * * \\
(1.066)\end{array}$ & $\begin{array}{c}3.386 * * \\
(1.356)\end{array}$ & $\begin{array}{l}1.807 * * \\
(0.847)\end{array}$ & L. Indusland & $\begin{array}{c}4.270 * * * \\
(1.408)\end{array}$ & $\begin{array}{c}3.875^{* * * *} \\
(1.190)\end{array}$ \\
\hline Gscitech & $\begin{array}{c}0.640 * * * \\
(0.142)\end{array}$ & $\begin{array}{l}-0.239 \\
(0.197)\end{array}$ & $\begin{array}{c}-0.499 * * \\
(0.231)\end{array}$ & $\begin{array}{l}-0.096 \\
(0.166)\end{array}$ & L. Gscitech & $\begin{array}{c}-0.863 * * * \\
(0.157)\end{array}$ & $\begin{array}{c}-0.401 * * \\
(0.198)\end{array}$ \\
\hline
\end{tabular}




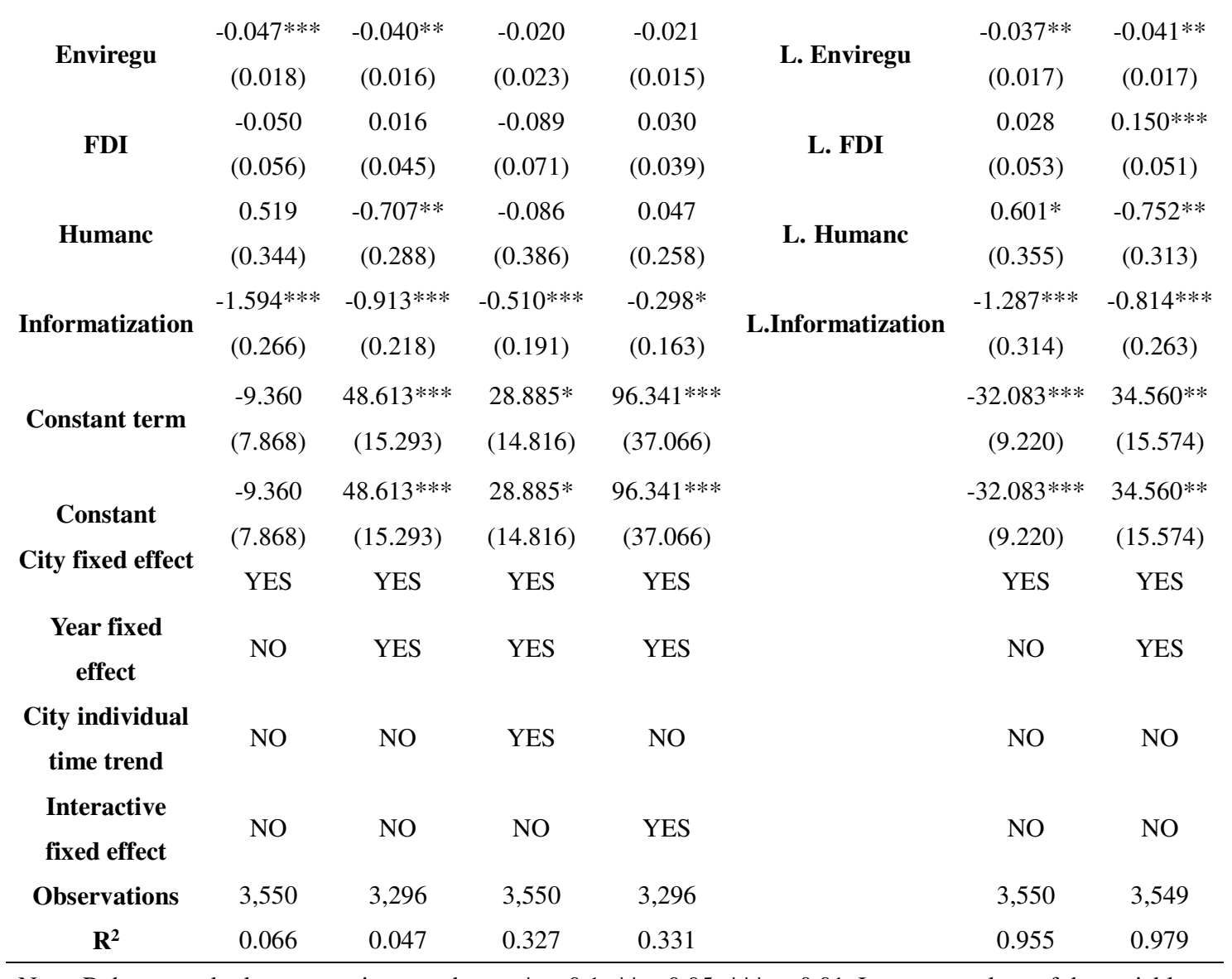

332

333

334

Note: Robust standard errors are in parentheses. ${ }^{*} \mathrm{p}<0.1 ;{ }^{*} \mathrm{p}<0.05 ; * * * \mathrm{p}<0.01$. L. represent lags of the variables.

In addition to fine particles, sulfur dioxide and nitrogen oxides are also major components of haze. Burning coal and oil not only causes smoke pollution, but also emits sulfur dioxide. Sulfur dioxide on the one hand endangers human health and on the other hand causes corrosion to buildings and metal materials. Nitrogen dioxide is the most toxic of nitrogen oxides and easily causes acute and chronic poisoning. Moreover, nitrogen dioxide is likely to be suspended in the air for a long time and is more likely to be inhaled. Therefore, this paper also uses the content of sulfur dioxide and nitrogen dioxide in air as the dependent variable to study the impact of urban innovation on haze pollution. ${ }^{2}$ Similar to the results of PM2.5, the results columns (1) and (2) of TABLE 3 illustrate that urban innovation is negative associated with sulfur dioxide and nitrogen dioxide pollution. Likewise, we also study the effect of lags of urban innovation on sulfur dioxide and nitrogen dioxide pollution to deal with reverse causality. The coefficients for lags of urban innovation are also statistically significant. The results of sulfur dioxide and nitrogen dioxide pollution imply that the improvement of urban innovation is associated with lower levels of haze pollution.

In the existing research on technological innovation and environmental pollution, only a few scholars, such as Liu (2018), have paid attention to haze pollution. However, Liu (2018) used annual average concentrations of PM10 to measure the haze pollution of each province. Compared with PM10, PM2.5 is smaller and rich in a large amount of toxic and harmful substances, which are more harmful

2 The data for sulfur dioxide and nitrogen dioxide comes from the China Environmental Statistics Yearbook, which only publishes data for some cities with monitoring stations, and most cities have missing data. 


\begin{tabular}{|c|c|c|c|c|}
\hline & (1) & (2) & (3) & (4) \\
\hline & $\mathrm{SO}_{2}$ & $\mathrm{SO}_{2}$ & $\mathrm{NO}_{2}$ & $\mathrm{NO}_{2}$ \\
\hline \multirow[t]{2}{*}{ LnUrbanInnov } & $-15.584 * * *$ & & $-4.109 *$ & \\
\hline & $(4.232)$ & & (2.304) & \\
\hline \multirow[t]{2}{*}{ L. LnUrbanInnov } & & $-15.934 * * *$ & & $-4.217 *$ \\
\hline & & (3.912) & & $(2.368)$ \\
\hline \multirow[t]{2}{*}{ Constant } & -31.176 & -47.764 & -59.723 & -63.006 \\
\hline & $(147.636)$ & (129.958) & $(56.881)$ & $(57.035)$ \\
\hline Control variable & YES & YES & YES & YES \\
\hline Year fixed effect & YES & YES & YES & YES \\
\hline City fixed effect & YES & YES & YES & YES \\
\hline Observations & 658 & 630 & 658 & 630 \\
\hline $\mathbf{R}^{2}$ & 0.385 & 0.403 & 0.051 & 0.053 \\
\hline
\end{tabular}

to human health and air environment quality. Therefore, this study mainly uses annual average concentrations of PM2.5 to measure haze pollution. Moreover, we also use other components of haze pollution — - the content of sulfur dioxide and nitrogen dioxide in the air as the explained variables for research, and also confirm that urban innovation is beneficial to reducing haze pollution. Therefore, this study fills the gap in the existing literature on innovation and haze pollution.

\section{TABLE 3 Impact of urban innovation on the concentration of $\mathrm{SO}_{2}$ and $\mathrm{NO}_{2}$}

Note: Robust standard errors are in parentheses. ${ }^{*} \mathrm{p}<0.1 ; * * \mathrm{p}<0.05 ; * * * \mathrm{p}<0.01$.

\subsection{Robustness Check}

In order to check the robustness of the effect of urban innovation on haze pollution, this paper also exploits a difference model as Equation (3) to examine if urban innovation is an explanatory variable for haze pollution. The difference model is based on the difference between the current value and the previous value of variables in the Equation (1) for regression, which can eliminate the influence of city fixed effects that do not change with time. Moreover, because urban innovation variable is in logarithmic form, the differential model uses the growth rate of urban innovation to perform regression analysis instead of absolute values, which can reduce the endogenous problem of Equation (1). Urban innovation reduces haze pollution, as shown in Column (1) of TABLE 4.

Since the PM2.5 concentration in the previous period may affect the current haze pollution level, this paper also uses the dynamic panel model as Equation (3) which adds explanatory variables the PM2.5 concentration of the previous period into the explanatory variables to assess the influence of urban innovation on haze pollution. The dynamic panel model is estimated using the difference generalized method of moments (GMM), the results reveal that urban innovation has negative effect on haze pollution (Column (2) of TABLE 4). In addition, we perform robustness check through studying the influence of urban innovation on the lowest or highest concentrations of PM.2.5 in each city in a year. The coefficients and significance of the core explanatory variables do not change much (Column (3)-(6) of TABLE 4), which is consistent with the previous research results. Overall, the results provide robust evidence that urban innovation is conducive to reducing haze pollution. 


\begin{tabular}{|c|c|c|c|c|c|c|}
\hline & (1) & (2) & (3) & (4) & (5) & (6) \\
\hline & D.PM2.5 & PM.2.5 & $\begin{array}{c}\text { PM2.5 } \\
\text { minimum }\end{array}$ & $\begin{array}{c}\text { PM2.5 } \\
\text { maximum }\end{array}$ & $\begin{array}{c}\text { PM2.5 } \\
\text { maximum }\end{array}$ & $\begin{array}{c}\text { PM2.5 } \\
\text { maximum }\end{array}$ \\
\hline L.pm2.5 & & $\begin{array}{c}0.093 * * * \\
(0.026)\end{array}$ & & & & \\
\hline LnUrbanInnov & & $\begin{array}{c}-4.248 * * * \\
(0.802)\end{array}$ & $\begin{array}{c}-1.709 * * * \\
(0.165)\end{array}$ & & $\begin{array}{c}-2.244 * * * \\
(0.235)\end{array}$ & \\
\hline D. LnUrbanInnov & $\begin{array}{c}-2.008 * * * \\
(0.582)\end{array}$ & & & & & \\
\hline L. LnUrbanInnov & & & & $\begin{array}{c}-1.444 * * * \\
(0.180)\end{array}$ & & $\begin{array}{c}-1.793 * * * \\
(0.274)\end{array}$ \\
\hline Constant & $\begin{array}{c}-1.082 * * \\
(0.523)\end{array}$ & $\begin{array}{c}-81.773 * * * \\
(23.895)\end{array}$ & $\begin{array}{l}-8.643 \\
(6.043)\end{array}$ & $\begin{array}{c}-26.263 * * * \\
(6.908)\end{array}$ & $\begin{array}{r}-10.740 \\
(9.962)\end{array}$ & $\begin{array}{c}-35.672 * * * \\
(11.483)\end{array}$ \\
\hline Control variable & YES & YES & YES & YES & YES & YES \\
\hline Year fixed effect & YES & YES & YES & YES & YES & YES \\
\hline City fixed effect & YES & YES & YES & YES & YES & YES \\
\hline Observations & 3,220 & 2,984 & 3,550 & 3,296 & 3,550 & 3,296 \\
\hline $\mathbf{R}^{2}$ & 0.017 & & 0.078 & 0.050 & 0.058 & 0.045 \\
\hline
\end{tabular}

Note: Robust standard errors are in parentheses. ${ }^{*} \mathrm{p}<0.1 ; * * \mathrm{p}<0.05 ; * * * \mathrm{p}<0.01$. D. is the difference operator.

In this part, we discuss how urban innovation affect haze pollution. According to the mechanism testing method of Chen and Chen (2018), this section tests the transmission mechanisms. Firstly, urban innovation may affect haze pollution by reducing energy consumption. On the one hand, a large number of suspended particles are generated during the energy utilization process which are important source for haze pollution. And the improvement of energy utilization efficiency and the use of clean energy can help alleviate pollution. On the other hand, the improvement of the level of urban innovation has led to an increase in energy efficiency (Subrahmanya and Kumar, 2011; Ramirez-Portilla et al., 2014; Cagno et al., 2015). In order to verify this mechanism, this paper selects the per capita social electricity consumption as the proxy variable of energy consumption. The results of the corresponding regression analysis were presented in TABLE 5. Columns (1) and (2) show that the regression coefficient of energy consumption is significantly positive, indicating that energy consumption exacerbates the haze pollution. The coefficient of urban innovation in columns (3) and (4) is negative and statistically significant, indicating that urban innovation can effectively reduce energy consumption. Therefore, the hypothesis that the increase of urban innovation will result in a decrease of energy consumption that mitigate haze pollution is verified. 


\begin{tabular}{|c|c|c|c|c|}
\hline & (1) & (2) & (3) & (4) \\
\hline & \multicolumn{2}{|c|}{$\begin{array}{l}\text { The impact of energy consumption on } \\
\text { PM2.5 }\end{array}$} & \multicolumn{2}{|c|}{$\begin{array}{l}\text { The impact of urban innovation on energy } \\
\text { consumption }\end{array}$} \\
\hline & PM2.5 & PM2.5 & Energy consumption & Energy consumption \\
\hline EnCsu & $\begin{array}{l}0.856^{* *} \\
(0.351)\end{array}$ & & & \\
\hline L. EnCsu & & $\begin{array}{l}0.794 * * \\
(0.346)\end{array}$ & & \\
\hline LnUrbanInnov & & & $\begin{array}{l}-0.037 * \\
(0.021)\end{array}$ & \\
\hline L. LnUrbanInnov & & & & $\begin{array}{l}-0.037 * \\
(0.021)\end{array}$ \\
\hline Constant & $\begin{array}{c}36.622 * * * \\
(5.835)\end{array}$ & $\begin{array}{c}26.533 * * * \\
(4.156)\end{array}$ & $\begin{array}{c}2.026 * * * \\
(0.705)\end{array}$ & $\begin{array}{c}2.426 * * * \\
(0.717)\end{array}$ \\
\hline Control variable & YES & YES & YES & YES \\
\hline Year fixed effect & YES & YES & YES & YES \\
\hline City fixed effect & YES & YES & YES & YES \\
\hline Observations & 3,488 & 3,254 & 3,484 & 3,232 \\
\hline $\mathbf{R}^{2}$ & 0.038 & 0.017 & 0.549 & 0.497 \\
\hline
\end{tabular}

Note: Robust standard errors are in parentheses. ${ }^{\mathrm{p}} \mathrm{p}<0.1 ; * * \mathrm{p}<0.05 ; * * \mathrm{p}<0.01$.

Secondly, another important mechanism for urban innovation to affect haze pollution is industrial agglomeration. On one hand, there are economies of scale environmental pollutant emissions and treatment (Lu and Feng, 2014), and agglomeration of economic activities are found to have a reducing effect on environmental pollution. On the other hand, urban space agglomeration of innovation was an important source for industrial agglomeration (Chung and Alcácer, 2002; Guastella and Van Oort, 2015; Goldman et al., 2016). The coefficients of the industrial agglomeration indicate that industrial agglomeration has a significant negative association with PM2.5 concentration in the air (Columns (1) and (2) of TABLE 6). Meanwhile, the estimated coefficient for urban innovation suggests a significant and positive association with industrial agglomeration (Columns (3) of TABLE 6). In addition, the result for lag of urban innovation is also statistically significant, implying that the advancement of urban innovation is associated higher levels of industrial agglomeration after correcting the reverse causality bias. Therefore, the transmission mechanism of urban innovation affecting haze pollution through industrial agglomeration does exist.

Past research found that technological innovation has improved energy efficiency and reduced energy consumption, which has reduced pollution (Sohag et al., 2015; Miao et al., 2017). This paper tests this transmission mechanism based on the research of city-level data in China. Moreover, on basis of research on innovation and industrial agglomeration, we have also found that innovation reduces haze pollution by influencing industrial agglomeration. 


\begin{tabular}{|c|c|c|c|c|}
\hline & (1) & (2) & (3) & (4) \\
\hline & \multicolumn{2}{|c|}{$\begin{array}{l}\text { The impact of industrial agglomeration } \\
\text { on PM2.5 }\end{array}$} & \multicolumn{2}{|c|}{$\begin{array}{c}\text { The impact of urban innovation on } \\
\text { industrial agglomeration }\end{array}$} \\
\hline & PM2.5 & PM2.5 & $\begin{array}{c}\text { Industrial } \\
\text { agglomeration }\end{array}$ & $\begin{array}{c}\text { Industrial } \\
\text { agglomeration }\end{array}$ \\
\hline InduAgg & $\begin{array}{c}-1.522 * * * \\
(0.459)\end{array}$ & & & \\
\hline L. InduAgg & & $\begin{array}{c}-1.869^{* * * *} \\
(0.492)\end{array}$ & & \\
\hline LnUrbanInnov & & & $\begin{array}{c}0.060 * * * \\
(0.020)\end{array}$ & \\
\hline L. LnUrbanInnov & & & & $\begin{array}{l}0.041^{*} \\
(0.021)\end{array}$ \\
\hline Constant & $\begin{array}{c}49.139 * * * \\
(6.954)\end{array}$ & $\begin{array}{c}18.401 * * \\
(7.882)\end{array}$ & $\begin{array}{c}9.820 * * * \\
(0.653)\end{array}$ & $\begin{array}{c}8.740 * * * \\
(0.690)\end{array}$ \\
\hline Control variable & YES & YES & YES & YES \\
\hline Year fixed effect & YES & YES & YES & YES \\
\hline City fixed effect & YES & YES & YES & YES \\
\hline Observations & 3,554 & 3,300 & 3,549 & 3,295 \\
\hline $\mathbf{R}^{2}$ & 0.040 & 0.035 & 0.678 & 0.623 \\
\hline
\end{tabular}

Note: Robust standard errors are in parentheses. ${ }^{*} \mathrm{p}<0.1 ; * *^{*} \mathrm{p}<0.05 ; * * \mathrm{p}<0.01$.

\subsection{Heterogeneity analysis of urban innovation affecting haze pollution}

The baseline regressions assume that urban innovation has the same impact on different time periods and regions. However, urban innovation and haze pollution in China show great differences in different time periods and different regions. The sample is then divided into sub-samples, by year 2013, to examine if the role of urban innovation differs among different time periods. Column (1) and (2) of TABLE 7 show that urban innovation significantly affects air pollution over time, and the reducing effects tend to increase as the year advances. The results are consistent with the reality that China has strengthened environmental regulations and technological innovations with environmentally friendly characteristics in recent years. Due to different economic development and institutional quality of different regions, we divide samples into eastern China, central China and western China. The corresponding regression results are presented in Column (3), (4) and (5) of TABLE 7 respectively, implying that urban innovation has a significant negative impact on the haze pollution in the eastern, central and western cities, but the impact effect is decrease for each in turn. This may be attributable to the fact that the eastern cities can provide better human resource, financial and infrastructure support for technological innovation, and the resource allocation and utilization efficiency are higher, thus the urban innovation can better exert the pollution reduction effect. 


\begin{tabular}{cccccc}
\hline & $(1)$ & $(2)$ & $(3)$ & $(4)$ & $(5)$ \\
& $2003-2012$ & $2013-2016$ & Eastern China & Middle of China & Western China \\
& PM2.5 & PM2.5 & PM2.5 & PM2.5 & PM2.5 \\
\hline LnUrbanInnov & $-2.372 * * *$ & $-2.785^{* * *}$ & $-2.954 * * *$ & $-2.169 * * *$ & $-1.410^{* * *}$ \\
& $(0.254)$ & $(0.830)$ & $(0.285)$ & $(0.322)$ & $(0.415)$ \\
Constant & -5.858 & $122.964 * * *$ & $-47.559 * * *$ & $-25.411 * *$ & $28.590^{* *}$ \\
Control variable & YES & $(39.847)$ & $(11.154)$ & $(11.984)$ & $(13.282)$ \\
Year fixed effect & YES & YES & YES & YES & YES \\
City fixed effect & YES & YES & YES & YES & YES \\
Observations & 2,512 & 1,038 & 1,479 & YES & YES \\
\multicolumn{1}{c}{$\mathbf{R}^{2}$} & 0.082 & 0.193 & 0.129 & 0.090 & 654 \\
\hline
\end{tabular}

Note: Robust standard errors are in parentheses. ${ }^{*} \mathrm{p}<0.1 ; * * \mathrm{p}<0.05 ; * * * \mathrm{p}<0.01$.

\section{Conclusions and Discussion}

Haze pollution is a serious environmental issue, it is of great significance to control pollution without affecting economic development. Innovation is integral to achieving the aims of improving the ecological environment. In this paper, we use PM2.5 concentration data from 2003 to 2016 of Chinese cities based on fixed-effect models to study the relationship between urban innovation and haze pollution. And we find that the improvement of urban innovation level significantly reduces PM2.5 concentration in the air. This conclusion remains unchanged after dealing with endogenous problems such as reverse causality. Moreover, urban innovation is also conducive to reducing the concentration of $\mathrm{SO}_{2}$ and $\mathrm{NO}_{2}$ in the air, thus alleviating haze pollution. Analysis of the transmission mechanism shows that urban innovation can alleviate haze pollution by reducing energy consumption and promoting industrial agglomeration. Moreover, the negative effects of urban innovation on haze pollution are increasing with time. And urban innovation has a greater mitigation effect on haze pollution in eastern cities than in central and western cities.

The technological innovation and urban agglomeration of innovation are important driving force for reducing haze pollution. There are many contents of haze pollution, including sulfur dioxide, nitrogen oxides and particulate matter. Reducing the production of these pollutants from the source is the key to reducing haze weather and improving air quality. To do this we need the joint efforts of governments of cities, enterprises and the general public to play a corresponding role in the process of managing the environment.

As the main source of pollutant emissions, factories and enterprises should increase their investment in energy conservation and emission reduction. Firstly, the most straightforward way is to improve the equipment to perform deep cleaning before the pollutants are released into the air, minimize $\mathrm{SO}_{2}, \mathrm{NO}_{\mathrm{X}}$ and particulate matter emissions. Secondly, it is possible to improve the total productivity of the entire enterprise through technological innovation, and to achieve the same performance with lower energy consumption, which helps to reduce the total amount of emissions. Thirdly, urban agglomeration of innovation activities will lead to reduction of haze pollution, the 
improvement of environmental pollution reduction efficiency can be achieved through cooperation and infrastructure sharing between enterprises in the city. Moreover, the scale effect brought by spatial agglomeration of innovation can increase the scale of returns of pollution control technologies across the whole city. Government of city should help to increase the innovation resources concentrating, and encourage green technology innovation. Moreover, governments of cities can also create a better institutional environment for enterprise innovation.

\section{References}

Acemoglu D, Aghion P, Bursztyn L, et al. The Environment and Directed Technical Change[J]. American Economic Review, 2012, 102.

Anand, M. M. Book Review: Regional Innovation Policy for Small-Medium Enterprises[J]. Global Business Review, 2004, 5(2).

Apergis N, Payne J E . Renewable energy, output, CO2 emissions, and fossil fuel prices in Central America: Evidence from a nonlinear panel smooth transition vector error correction model[J]. Energy Economics, 2014, 42:226 - 232.

Baniak A, Dubina I. Innovation Analysis and Game Theory: a Review[J]. Innovation, 2012, 14(2): 178-191.

Bhupendra K V, Sangle S. What drives successful implementation of pollution prevention and cleaner technology strategy? The role of innovative capability[J]. Journal of Environmental Management, 2015, 155:184 - 192.

Cagno E, Ramirez-Portilla A, Trianni A . Linking energy efficiency and innovation practices: Empirical evidence from the foundry sector[J]. Energy Policy, 2015, 83:240 - 256. Chen S Y, Chen D K. Haze pollution, government governance and high-quality economic development[J]. Economic Research, 2018,53(02):20 - 34.

Chertow M R , Ashton W S , Espinosa J C . Industrial Symbiosis in Puerto Rico:

Environmentally Related Agglomeration Economies[J]. Regional Studies, 2008, 42(10):1299 -1312 .

Chung W, Alcácer, J. Knowledge Seeking and Location Choice of Foreign Direct Investment in the United States[J]. Management Science, 2002, 48(12):1534 - 1554. Copeland B R, Taylor M S . North-South Trade and the Environment[J]. The Quarterly Journal of Economics, 1994, 109(3):755 - 787.

Daddi T, Nucci B, Iraldo F. Using Life Cycle Assessment(LCA)to Measure the Environmental Benefits of Industrial Symbiosis in an Industrial Cluster of SMEs [J]. Journal of Cleaner Production, 2017, 147 (01): 157-164.

Demir C, Cergibozan R, Ari A. Environmental Dimension of Innovation: Time Series Evidence from Turkey[J]. Environment, Development and Sustainability, 2019.

Dinda S. Production technology and carbon emission: long-run relation with short-run dynamics[J]. Journal of Applied Economics, 2018, 21(1):106-121. 
Ehrlich P R, Holdren J P. Impact of Population Growth[J]. Science, 1971, 171(3977):1212 1217.

Forman C, Goldfarb A, Greenstein S. Agglomeration of Invention in the Bay Area: Not Just ICT[J]. American Economic Review, 2016, 106(5):146 - 151.

Ge M. Dynamic Relationship Between Technology Innovation of Industrial Enterprises and Environmental Pollution: A Case Study of Zhejiang Province, China.[J]. Nature Environment \& Pollution Technology, 2019,18(2): 531-536.

Giuliani E. Regulating global capitalism amid rampant corporate wrongdoing-Reply to "Three frames for innovation policy"[J]. Research Policy, 2018, 47(9):1577-1582. Goldman D B, Klier T, Walstrum T. Evidence on the Within-Industry Agglomeration of R\&D, Production, and Administrative Occupations[J]. Social Science Electronic Publishing, 2016.

Grossman G M, Krueger A B. Environmental Impacts of a North American Free Trade Agreement[J]. Social Science Electronic Publishing, 1991, 8(2):223 - 250.

Guastella G, Van Oort F G. Regional Heterogeneity and Interregional Research Spillovers in European Innovation: Modelling and Policy Implications[J]. Regional Studies, 2015, 49(11):1772 - 1787.

Hafeez M, Yuan C, Khelfaoui I, et al. Evaluating the Energy Consumption Inequalities in the One Belt and One Road Region: Implications for the Environment[J]. Energies, 2019, 12.

Herrerias M J, Cuadros A, Luo D. Foreign versus indigenous innovation and energy intensity: Further research across Chinese regions[J]. Applied Energy, 2016, 162: 1374 1384.

Hosoe M, Naito T. Trans-boundary pollution transmission and regional agglomeration effects[J]. Papers in Regional Science, 2006, 85(1):99-120.

Hospers G, Governance in innovative cities and the importance of branding, Innovation, 2008, 10:2-3,224-234.

Ibrahiem D M. Do Technological Innovations and Financial Development Improve Environmental Quality in Egypt? [J]. Environmental Science and Pollution Research, 2020:1-13.

Johnstone N, Managi S, Rodriguez M C, et al. Environmental policy design, innovation and efficiency gains in electricity generation[J]. Energy Economics, 2017, 63:106-115. Levinson A. Technology, International Trade, and Pollution from US Manufacturing[J]. American Economic Review, 2009, 99(5):2177-2192.

Li Y G, Zhang P. Does Industrial Agglomeration Increase China's Environmental Pollution? Empirical Evidence from China's Provincial Level[J]. Journal of Huazhong University of Science and Technology (Social Science Edition), 2013, 27(05): 97 - 106.

Liu X H. Dynamic evolution, spatial spillover effect of technological innovation and haze pollution in China. Energy Environ. 2018, 29, 968-988.

Lu M, Feng H. Agglomeration and emission reduction: Empirical Study on the impact of urban scale gap on industrial pollution intensity[J]. World Economy, 2014(7):86 - 114. 
Ma Y, Cao H, Ma Y, et al. Does technological innovation reduce water pollution intensity in the context of informal environmental regulation?[J]. Asia-Pacific Journal of Chemical Engineering, 2020(8).

Marshall, A. Principles of Economics. London: MacMillan, 1890.

Miao C, Fa Ng D, Sun L, et al. Driving Effect of Technology Innovation on Energy

Utilization Efficiency in Strategic Emerging Industries[J]. Journal of Cleaner Production, 2017, 170.

Nguyen T T, Pham T, Tram H. Role of information and communication technologies and innovation in driving carbon emissions and economic growth in selected G-20 countries[J]. Journal of Environmental Management, 2020, 261(May1): 110162.1-110162.10.

Nyarko M C, Long X, Baah B K, et al. The effect of innovation on CO2 emissions of OCED countries from 1990 to 2014[J]. Environmental Science and Pollution Research, 2018, 25.

Porter M E. Clusters and the new economics of competition[J]. Harvard business review, 1998, 76: 77 - 90.

Prakash A, Potoski M. Racing to the Bottom? Trade, Environmental Governance, and ISO 14001[J]. American Journal of Political Science, 2006, 50(2):350 - 364.

Ramirez-Portilla A, Cagno E, Trianni A . Is Innovation an Enabler of Energy Efficiency? An Exploratory Study of the Foundry Sector[J]. Energy Procedia, 2014, 61:1191 - 1195. Sohag K, Begum R A, Abdullah S M S, et al. Dynamics of energy use, technological innovation, economic growth and trade openness in Malaysia[J]. Energy, 2015, 90: 1497-1507.

Subrahmanya M H B, Kumar R S. Technological innovations and energy intensity of machine tool SMEs in Bangalore: Do process innovations contribute to energy efficiency? [J].International Journal of Energy Technology and Policy, 2011, 7(516): 519-536. Sultan S S, Dijk M P. Palestinian clusters: from agglomeration to innovation[J]. European Scientific Journal, 2017, 13(13): 323 - 336.

Valentin P, Elena C. The impact of the innovation process on sustainable development strategies and policies[J]. Economica. 2020, 111: 7-21.

Van Donkelaar, A., R. V. Marin, M. Brauer, N. C. Hsu, R. A. Kahn, R. C. Levy, A. Lyapustin, A. M. Sayer, and D. M. Winker. 2018. Global Annual PM2.5 Grids from MODIS, MISR and SeaWiFS Aerosol Optical Depth (AOD) with GWR, 1998-2016. Palisades NY: NASA Socioeconomic Data and Applications Center (SEDAC).

Wan L, Luo B, Li T, et al. Effects of technological innovation on eco-efficiency of industrial enterprises in China[J]. Nankai Business Review International, 2015. Wang P, Xie L. Pollution control investment, enterprise technological innovation and pollution control efficiency [J]. China's population resources and environment, 2014(9):51-58.

Wu J. Research on the Impact of Technological Innovation on Environmental Pollution -Based on the Moderating Effect of Internet Development[J]. E3S Web of Conferences, 2020, 143(2):02054. 
Xu F, Ma L, Li X, et al. Capital Enrichment, Innovation Capability and Environmental Pollution Effect: Evidence from China's Manufacturing Industry[J]. Nature Environment and Pollution Technology, 2020, 19(3):1141-1148.

Yang R F. Industrial Agglomeration and Regional Wage Gap_-Based on Empirical Study of 269 Cities in China[J]. Management World, 2013(8): 41-52.

Yang R F, Li S S, Can the Innovation Pilot Policy Lead Enterprise Innovation-Micro-Evidence from the National Innovative City Pilot[J]. Statistical Research, 2020(12): 32-45.

Yang Z B, Shao S, Yang L L, et al. Improvement pathway of energy consumption structure in China's industrial sector: From the perspective of directed technical change[J]. Energy Economics, 2018, 72:166-176.

Zeng H, Li H. Research on the coordinated development of green innovation, environmental pollution and energy consumption[J]. IOP Conference Series: Earth and Environmental Science, 2020, 440(4):042010 (7pp).

Zhang K, Jiang W, Zhang S, et al. The impact of differentiated technological innovation efficiencies of industrial enterprises on the local emissions of environmental pollutants in Anhui province, China, from 2012 to 2016[J]. Environmental Science and Pollution Research, 2019, 26(26):27953-27970.

\section{Declarations}

\section{Ethical Approval and Consent to Participate}

Not applicable

\section{Consent for publication}

Not applicable

\section{Availability of data and materials}

The dataset used in this study were obtain from China Urban and Industrial Innovation Report 2017, and China National Bureau of Statistics.

\section{Competing interests}

The authors declare that they have no competing interests.

\section{Funding}

This work was supported by China National Social Science Fund (Grant No. 20FJLB023).

\section{Authors Contributions}

Lingyun He: Conceptualization, Formal analysis, Methodology, Software, Funding acquisition, Writing-original draft. Enyu Yuan: Validation, Supervision, Project administration. Kexin Yang: Data curation, Visualization. Dongjie Tao: Writing-review \& editing, Resources. 